\title{
Effects of rosiglitazone pretreatment on blood glucose, lipid levels, urea, and microalbuminuria in rats undergoing $70 \%$ pancreatectomy
}

This article was published in the following Dove Press journal:

Open Access Surgery

3 January 2013

Number of times this article has been viewed

\author{
Hasan Zafe Acar' \\ Oytun Okan Senel ${ }^{2}$ \\ Neslihan Bukan ${ }^{3}$ \\ Banu Yurekli ${ }^{4}$ \\ A Ebru Salman ${ }^{5}$ \\ Fahri Yetisir ${ }^{6}$ \\ 'Yozgat Bozok University Hospital, \\ General Surgery Department, Yozgat, \\ ${ }^{2}$ Department of Surgery, Faculty \\ of Veterinary Medicine, Ankara \\ University, Ankara, ${ }^{3}$ Department \\ of Medical Biochemistry, Gazi \\ University, Ankara, ${ }^{4}$ Department \\ of Endocrinology, Bozyaka Research \\ and Training Hospital, Izmir, \\ ${ }^{5}$ Department of Anesthesiology \\ and Reanimation, ${ }^{6}$ Department \\ of General Surgery, Ataturk Research \\ and Training Hospital, Ankara, Turkey
}

Correspondence: Fahri Yetisir Mustafa Kemal mah.2157. street. II/8 Çankaya/ANKARA/TURKEY Fax +03123210089 Email drfahriyetisir@hotmail.com
Background: Partial pancreatectomy is one of the main causes of type II diabetes, which occurs because of insulin deficiency due to a decrease in the number of $\beta$-cells. Partial pancreatectomy is the treatment of choice particularly for pancreatic cysts, benign and malign tumors of the pancreas, and pancreatic abscesses. Morbidity and mortality associated with pancreatectomy increases as a result of diabetes and its complications.

Purpose: This experimental study was designed to investigate the effects of rosiglitazone pretreatment on blood glucose, lipid, urea, and microalbuminuria levels in rats undergoing $70 \%$ pancreatectomy.

Material and methods: Twelve Wistar albino rats weighing 180-230 g were randomized into two groups. The study group $(\mathrm{n}=6)$ received rosiglitazone $(10 \mathrm{mg} / \mathrm{kg} /$ day $)$ orally for 4 weeks before and after pancreatectomy. The control group $(n=6)$ received vehicle. At the end of the fourth week, all rats underwent pancreatectomy, which was performed by removing $70 \%$ of their pancreatic tissue. Blood samples were taken from the tail veins at postoperative day one, week two, and week four for analysis of blood glucose, triglyceride, cholesterol, and urea levels. Urine was collected from the bladder for microalbuminuria analysis.

Results: Blood glucose levels in the study group were significantly lower than the control group at postoperative day one, week two, week four $(P=0.01, P=0.004$, and $P=0.005$, respectively). Significant microalbuminuria was present at postoperative week four when compared to the control group $(P<0.05)$. Triglyceride, cholesterol, and urea levels were within normal limits.

Conclusion: This study showed that pretreatment of rosiglitazone increased the tolerance to diabetes in rats undergoing partial pancreatectomy.

Keywords: rosiglitazone, partial pancreatectomy, diabetes

\section{Introduction}

Partial pancreatectomy, performed particularly for reasons such as pancreatic cysts, benign and malignant tumors of the pancreas, or pancreatic abscesses, may result in diabetes. Partial pancreatectomy is one of the main causes of type II diabetes. ${ }^{1}$ Many studies have tried increasing the activity of $\beta$-cells with drug pretreatments to reduce the complications of diabetes. ${ }^{2-4}$ It has been speculated that persistent insulin resistance accelerates $\beta$-cell failure. Earlier intervention correcting insulin resistance or protecting $\beta$-cells may prevent the development and progression of diabetes. A decrease in insulin resistance and hyperglycemia may delay $\beta$-cell failure in type II diabetes. ${ }^{5} \mathrm{~K}$ won et al used long-term fermented soybean derivatives in rats subjected to $90 \%$ pancreatectomy and it was revealed that hepatic insulin resistance can be reduced. ${ }^{2}$ 
Kwon et al also found that insulinotropic effects of fermented soybean are higher than cooked soybean in rats undergoing $90 \%$ pancreatectomy. ${ }^{3}$ Bonner-Weir et al observed that the remaining pancreatic tissue was regenerated after 8 weeks in rats subjected to $90 \%$ pancreatectomy. ${ }^{1}$

Rosiglitazone is a peroxisome proliferator-activated receptor- $\gamma$ (PPAR- $\gamma$ ) agonist that belongs to the nuclear hormone receptor superfamily of ligand-activated transcription factors. ${ }^{6}$ It has been shown to have an important role in various biological processes including adipogenesis, glucose metabolism, and lipid metabolism. ${ }^{6,7}$ PPAR- $\gamma$ is expressed in the $\beta$-cells of both rodents and humans. ${ }^{6,8}$ Treatment of diabetes with PPAR- $\gamma$ agonists improves islet architecture, insulin content, and glucose-stimulated insulin secretion. ${ }^{6,9}$

The aim of the current study was to investigate the effect of rosiglitazone on the blood glucose, lipid, urea, and microalbuminuria levels in rats undergoing $70 \%$ pancreatectomy.

\section{Material and methods}

This experimental study was performed with the approval of the ethics committee of Gazi University Hospital (Ankara, Turkey). Twelve male Wistar albino rats (obtained from Gazi University Animal Laboratory) (3 months old) weighing 180-230 g were used in this study. Animals were housed in cages under controlled environmental conditions at $22^{\circ} \mathrm{C}$ with a 12-hour light/dark cycle. The rats were randomly assigned into two groups equally. All animals had free access to standard laboratory diet and water throughout the experimental period. On an empty stomach, all animals were given either vehicle ( $1 \%$ carboxymethyl cellulose at $3 \mathrm{~mL} / \mathrm{kg}$ ) or rosiglitazone (10 $\mathrm{mg} / \mathrm{kg} /$ day) by oral gavage for 8 weeks. In the fourth week of the study, $70 \%$ surgical pancreatectomy was performed on all the rats in both groups.

\section{Surgical procedure}

Animals were fasted overnight and anesthetized by intraperitoneal administration of $40 \mathrm{mg} / \mathrm{kg}$ ketamine and $5 \mathrm{mg} / \mathrm{kg}$ xylazine. All pancreatic tissue was removed by gentle abrasion with a cotton applicator, except for an anatomically well-defined remnant which is bordered by a branch of the hepatic portal vein and the first portion of the duodenal loop. The incisions were sutured using absorbable 6-0 vicryl sutures (Ethicon, Johnson \& Johnson, New Brunswick, NJ, USA). After surgery, the rats were given access to food and water ad libitum. In the second and fourth week after surgery, fasting plasma glucose concentrations were measured daily at 4:00-5:00 PM. All animals received an intraperitoneal injection of gentamicin $(3 \mathrm{mg} / \mathrm{kg}$ body weight), ampicillin and cloxacillin ( $20 \mathrm{mg} / \mathrm{kg}$ body weight), and diclofenac sodium $(0.5 \mathrm{mg} / \mathrm{kg}$ body weight) for 3 days starting from the operative day. Blood samples were collected from the tail veins for analysis of blood glucose, triglyceride, cholesterol, urea levels. Urine samples were collected by cystocentesis for measurement of microalbuminuria levels at postoperative day one, week two, and week four. All rats were sacrificed by thiopental injection at the end of the study.

\section{Statistical analysis}

Statistical analysis was performed with NCSS 2007 for Windows (NCSS, LLC, Kaysville, UT, USA). The Wilcoxon signed-rank test was used in the comparison of intragroup measurements. Change values in percentage (Mann-Whitney $U$ test) were used in the comparison of study and control groups. $P<0.05$ was accepted as statistically significant.

\section{Results}

Fasting blood glucose, triglyceride, cholesterol, urea, and microalbuminuria levels at postoperative day one, week two, and week four of the study and control groups are shown in Table 1. Postoperative blood glucose levels of the study group at day one, week two, and week four were significantly lower than the control group $(P=0.01, P=0.004$, and $P=0.005$, respectively).

Statistically significant changes were observed in postoperative blood glucose levels of the study group between day one, week two, and week four $(P=0.002)$. Postoperative day one blood glucose levels of the study group were significantly higher compared to week two and week four levels $(P=0.028$ and $P=0.027$, respectively). Postoperative week two blood glucose levels of the study group were higher compared to postoperative week four levels $(P=0.028)$. Significant changes were observed in postoperative blood glucose levels of the control group between day one, week two, and week four $(P=0.03)$. Postoperative blood glucose levels of the control group on day one were significantly higher compared to week four levels $(P=0.043)$, but no significant difference was observed among other times $(P>0.05)$. Microalbuminuria levels were not different between groups at postoperative day one and week two. Microalbuminuria at postoperative week four was significantly lower in the study group $(P<0.05)$.

No significant difference was observed in postoperative blood triglyceride, urea, and cholesterol levels between the 
Table I Comparisons of blood fasting glucose, triglyceride, cholesterol, urea, and microalbuminuria levels in study and control group on postoperative day one, week two, and week four

\begin{tabular}{|c|c|c|c|}
\hline & Study group & Control group & $P$ \\
\hline \multicolumn{4}{|c|}{ Blood glucose } \\
\hline Day one & I 44.5 (| $40.25-\mid 52)$ & $192(157.25-292.75)$ & $0.01 *$ \\
\hline Week two & $113(103.25-123.75)$ & $186(146-264)$ & $0.004 *$ \\
\hline Week four & $105.5(100.5-113)$ & $183.5(130.25-229.25)$ & $0.005^{*}$ \\
\hline$P$ & $0.002 *$ & $0.03^{*}$ & \\
\hline \multicolumn{4}{|c|}{ Triglyceride } \\
\hline Day one & $100.5(66-130.75)$ & $121.5(88-132.25)$ & 0.749 \\
\hline Week two & $103(7|-| 28)$ & 87 (72.75-137.5) & 0.873 \\
\hline Week four & $97(77.5-134.25)$ & 85.5 (73.25-99.25) & 0.262 \\
\hline \multicolumn{4}{|c|}{ Cholesterol } \\
\hline Day one & $62(58.75-69.25)$ & $68.5(54.25-73)$ & 0.422 \\
\hline Week two & $47(37.5-62)$ & $64(54.25-70.75)$ & 0.091 \\
\hline Week four & $52(45-65.25)$ & $46.8(37.38-63.83)$ & 0.423 \\
\hline \multicolumn{4}{|l|}{ Urea } \\
\hline Day one & $38.85(35.12-43.65)$ & $37.3(35.6-47.7)$ & 0.873 \\
\hline Week two & $36.9(32.07-42.2)$ & $41.1(35.05-45.5)$ & 0.378 \\
\hline Week four & $38.15(35.5-46.65)$ & $46.8(37.37-63.82)$ & 0.229 \\
\hline \multicolumn{4}{|c|}{ Microalbuminuria } \\
\hline Day one & $0(0-0)$ & $0(0-0)$ & \\
\hline Week two & $0.0(0.0-8.0)$ & $17.5(0.0-42.0)$ & \\
\hline Week four & $0.0(0.0-8.0)$ & $26.0(0.0-38.0)$ & $0.049 *$ \\
\hline
\end{tabular}

Note: *Indicates significance at 0.05 .

study and control groups at day one, week two, and week four ( $P>0.05, P=0.277$, and $P=0.180$, respectively).

\section{Discussion}

Rosiglitazone is included in the thiazolidinedione class of drugs, which are insulin sensitizers currently used for the treatment of type II diabetes. Rosiglitazone reduces insulin resistance and enhances insulin sensitivity by acting as ligands for the transcription PPAR- $\gamma$, which is predominantly expressed in adipose tissue. ${ }^{7,10}$ It modulates the key communication signals between fat and muscle. It also has many other beneficial nonglycemic properties such as decreasing blood pressure, triglycerides, vascular resistance, and inflammation, increasing high-density lipoprotein cholesterol, and improving endothelial cell function. ${ }^{7,11}$ Activation of PPAR- $\gamma$ has been shown to attenuate growth of various cultured cell lines such as those from cancers of adipose tissue, liver, pancreatic acinar tissue, prostate, and lung. ${ }^{6}$

The potential side effects of thiazolidinediones include edema and hemodilution. It is possible that lowering hematocrit is a secondary response to rosiglitazone-induced vasodilatation, which in turn activates the renin-angiotensin system, with subsequent hemodilution as a consequence of sodium and water retention. ${ }^{12}$
The beneficial effect of rosiglitazone on vascular reactivity is mediated by activation of endothelial PPAR- $\gamma$ receptors, leading to increased nitric oxide synthesis. This production leads partly to a decrease in blood pressure in both human and animal models. ${ }^{12}$

According to the results of the current study, treatment with rosiglitazone before $70 \%$ pancreatectomy has significant effects on reducing the blood glucose levels. There were no changes in blood lipid levels of the two groups according to the data obtained at postoperative day one, week two, and week four. Microalbuminuria levels were observed to be lower in the study group than the control group at postoperative week four. The emergence of microalbuminuria is an important indicator of damage to renal endothelial cells caused by diabetes. Imano et al investigated the effect of troglitazone therapy for 12 weeks on microalbuminuria in patients with incipient diabetes, demonstrating that troglitazone decreased microalbuminuria significantly. ${ }^{13}$ Another study on patients with type II diabetes, examining the effects of rosiglitazone on albumin excretion in urine, showed that this drug has positive effects in decreasing renal and vascular complications of diabetes. ${ }^{14}$ Agrawal et al used rosiglitazone in renal insufficient patients who were taking sulfonylurea and reported that the patients tolerated this therapy well. ${ }^{15}$ Pistrosch et al showed in patients with type II diabetes that insulin resistance and microalbuminuria are in direct relationship, and emphasized that rosiglitazone fixes renal endothelial dysfunction, improves glomerular hyperfiltration, and decreases microalbuminuria. ${ }^{16}$

Heyliger et al emphasized that vanadium controls high blood glucose levels and prevents a decline in cardiac performance in rats. ${ }^{4}$ Tozzo et al and Harrity et al studied with $\mathrm{db} / \mathrm{db}$ mice and revealed that muraglitazar, a PPAR- $\alpha / \gamma$ activator, prevents the natural progression of diabetes by correcting insulin resistance and preserving islet mass and $\beta$-cell function. ${ }^{5,17}$ Drugs in this category have been shown to prevent diabetes or decrease its adverse effects in recent studies, by PPAR- $\gamma$ activation or by directly protecting $\beta$-cells. ${ }^{6,10,18}$ PPAR- $\gamma$ activation shows its effect by stimulating adiponectin levels, helping to preserve $\beta$-cell function, prevent insulin resistance and $\beta$-cell apoptosis, and the need for insulin secretion. ${ }^{19-21}$ Rosiglitazone can act directly on $\beta$-cells, and indirectly improve insulin sensitivity. Han et al showed that rosiglitazone can inhibit the early stage of glucolipotoxicity-induced $\beta$-cell apoptosis. ${ }^{22} \mathrm{Kim}$ et al showed that rosiglitazone increased glucose transporter-2, glucokinase, and BETA2/NeuroD gene expression. ${ }^{23}$ Similarly, in the current study, rosiglitazone may have demonstrated its effect 
by stimulating insulin secretion. Yilmaz et al found that significant improvement was observed in hemoglobin A1c in the insulin plus rosiglitazone (2.4\%) group when compared to the insulin group. Daily total insulin dose was 12.7 units/day in the insulin group, which was decreased to 4.7 units/day in the insulin plus rosiglitazone group. No serious adverse events were observed in either group. ${ }^{24}$

Recent reports have highlighted the significant increase in cardiac morbidity and mortality in humans with type II diabetes mellitus. However, there are conflicting reports on the importance of rosiglitazone as a cardioprotective agent in postmyocardial infarction. ${ }^{12}$ Therefore, it is speculated that multifactorial factors take place in the effect of rosiglitazone on cardiovascular function, and therefore its use should be tailored for each individual patient at risk for cardiac failure.

\section{Conclusion}

In conclusion, treatment with rosiglitazone monotherapy, when initiated before the onset of diabetes, prevents the emergence of diabetes and may attenuate subsequent characteristics of diabetes in rats undergoing partial pancreatectomy.

\section{Disclosure}

The authors report no conflicts of interest in this work.

\section{References}

1. Bonner-Weir S, Trent DF, Weir GC. Partial pancreatectomy in the rat and subsequent defect in glucose-induced insulin release. J Clin Invest. 1983;71(6):1544-1553.

2. Kwon DY, Hong SM, Lee JE, Sung SR, Park S. Long-term consumption of fermented soybean-derived Chungkookjang attenuates hepatic insulin resistance in 90\% pancreatectomized diabetic rats. Horm Metab Res. 2007;39(10):752-757.

3. Kwon DY, Jang JS, Hong SM, et al. Long-term consumption of fermented soybean-derived Chungkookjang enhances insulinotropic action unlike soybeans in $90 \%$ pancreatectomized diabetic rats. Eur J Nutr. 2007;46(1): 44-52.

4. Heyliger CE, Tahiliani AG, McNeill JH. Effect of vanadate on elevated blood glucose and depressed cardiac performance of diabetic rats. Science. 1985;227(4693):1474-1477.

5. Tozzo E, Ponticiello R, Swartz JA, et al. The dual peroxisome proliferator-activated receptor alpha/gamma activator muraglitazar prevents the natural progression of diabetes in $\mathrm{db} / \mathrm{db}$ mice. J Pharmacol Exp Ther. 2007;321(1):107-115.

6. Rosen DE, Kulkarni RN, Sarraf P, et al. Targeted elimination of peroxisome proliferator-activated receptor gamma in beta cells leads to abnormalities in islet mass without compromising glucose homeostasis. Mol Cell Biol. 2003;23(20):7222-7229.
7. Baldwin D Jr, Duffin KE. Rosiglitazone treatment of diabetes mellitus after solid organ transplantation. Transplantation. 2004;77(7):1009-1014.

8. Dubois M, Pattou F, Kerr-Conte J, et al. Expression of peroxisome proliferator-activated receptor gamma (PPARgamma) in normal human pancreatic islet cells. Diabetologia. 2000;43(9):1165-1169.

9. Berkowitz K, Peters R, Kjos SL, et al. Effect of troglitazone on insulin sensitivity and pancreatic beta-cell function in women at high risk for NIDDM. Diabetes.1996;45(11):1572-1579.

10. Lin CY, Gurlo T, Haataja L, Hsueh WA, Butler PC. Activation of peroxisome proliferator-activated receptor gamma by rosiglitazone protects human islet cells against human islet amyloid polypeptide toxicity by a phosphatidylinositol 3'-kinase dependent pathway. J Clin Endocrinol Metab. 2005;90(12):6678-6686.

11. Araujo CV, Estatoo V, Tibiriça E, Bozza PT, Castro-Fario-Neto HC, Silva AR. PPAR gamma activation protects the brain against microvascular dysfunction in sepsis. Microvasc Res. 2012;84:218-221.

12. Ogino T, Zhu M, Murakami T, Kuwajima M, Shima K. Effect of partial pancreatectomy on beta-cell mass in the remnant pancreas of Wistar fatty rats. J Med Invest. 1998;45(1-4):103-110.

13. Imano E, Kanda T, Nakatani Y, et al. Effect of troglitazone on microalbuminuria in patients with incipient diabetic nephropathy. Diabetes Care. 1998;21(12):2135-2139.

14. Bakris G, Viberti G, Weston WM, Heise M, Porter LE, Freed MI. Rosiglitazone reduces urinary albumin excretion in type II diabetes. J Hum Hypertens. 2003;17(1):7-12.

15. Agrawal A, Sautter MC, Jones NP. Effects of rosiglitazone maleate when added to a sulfonylurea regimen in patients with type 2 diabetes mellitus and mild to moderate renal impairment: a post hoc analysis. Clin Ther. 2003;25(11):2754-2764.

16. Pistrosch F, Herbrig K, Kindel B, Passauer J, Fischer S, Gross P. Rosiglitazone improves glomerular hyperfiltration, renal endothelial dysfunction, and microalbuminuria of incipient diabetic nephropathy in patients. Diabetes. 2005;54(7):2206-2211.

17. Harrity T, Farrelly D, Tieman A, et al. Muraglitazar, a novel dual (alpha/gamma) peroxisome proliferator-activated receptor activator, improves diabetes and other metabolic abnormalities and preserves beta-cell function in db/db mice. Diabetes. 2006;55(1):240-248.

18. Yoshikawa H, Tajiri Y, Sako Y, Hashimoto T, Umeda F, Nawata H. Effects of free fatty acids on beta-cell functions: a possible involvement of peroxisome proliferator-activated receptors alpha or pancreatic/ duodenal homeobox. Metabolism. 2001;50(5):613-618.

19. Goldberg RB, Kendall DM, Deeg MA, et al. A comparison of lipid and glycemic effects of pioglitazone and rosiglitazone in patients with type 2 diabetes and dyslipidemia. Diabetes Care. 2005;28(7):1547-1554.

20. Luther P, Baldwin D Jr. Pioglitazone in the management of diabetes mellitus after transplantation. Am J Transplant. 2004;4(12):2135-2138.

21. Meier JM, McGarry JD, Faloona GR, Unger RH, Foster DW. Studies of the development of diabetic ketosis in the rat. J Lipid Res. 1972;13(2): 228-233.

22. Han SJ, Kang ES, Hur KY, et al. Rosiglitazone inhibits early stage of glucolipotoxicity-induced beta-cell apoptosis. Horm Res. 2008;70(3): $165-173$.

23. Kim HS, Noh JH, Hong SH, et al. Rosiglitazone stimulates the release and synthesis of insulin by enhancing GLUT-2, glucokinase and BETA2/NeuroD expression. Biochem Biophys Res Commun. 2008; 367(3):623-629.

24. Yilmaz H, Gursoy A, Sahin M, Guvener Demirag N. Comparison of insulin monotherapy and combination therapy with insulin and metformin or insulin and rosiglitazone or insulin and acarbose in type 2 diabetes. Acta Diabetol. 2007;44(4):187-192. 
Open Access Surgery

\section{Publish your work in this journal}

Open Access Surgery is an international, peer-reviewed, open access journal that focuses on all aspects of surgical procedures and interventions. Patient care around the peri-operative period and patient outcomes post surgery are key topics. All grades of surgery from minor cosmetic interventions to major surgical procedures are covered. Novel techniques

and the utilization of new instruments and materials, including implants and prostheses that optimize outcomes constitute major areas of interest. The manuscript management system is completely online and includes a very quick and fair peer-review system. Visit http://www.dovepress.com/ testimonials.php to read real quotes from published authors. 